\title{
Instrumentos de caráter jurídico e técnico de suporte à adoção do programa de despesas públicas e responsabilidade financeira (PEFA) na avaliação da gestão das
}

\section{finanças públicas municipal}

\author{
Technical and legal instruments to support the adoption of the public expenditure and financial \\ responsibility program (PEFA) in the evaluation of municipal public finance management \\ Instrumentos técnicos y legales para apoyar la adopción del programa de gasto público y \\ responsabilidad financiera (PEFA) enlaevaluación de lagestión de las finanzas públicas municipales
}

Recebido: 08/03/2021 | Revisado: 14/03/2021 | Aceito: 23/03/2021 | Publicado: 30/03/2021

Rosenália Ramalho Teixeira

ORCID: https://orcid.org/0000-0003-1407-5890 Universidade Federal dos Vales do Jequitinhonha e Mucuri, Brasil E-mail: rosenalia.teixeira@ufvjm.edu.br

Carlos Alberto Dias

ORCID: https://orcid.org/0000-0002-5286-6637 Universidade Federal dos Vales do Jequitinhonha e Mucuri, Brasil E-mail: carlos.dias@ufvjm.edu.br

Ciro Meneses Santos

ORCID: https://orcid.org/0000-0001-8687-0987 Universidade Federal dos Vales do Jequitinhonha e Mucuri, Brasil E mail: cirosantos@gmail.com

Geórgia Fernandes Barros

ORCID: https://orcid.org/0000-0003-1362-9548 Universidade Federal dos Vales do Jequitinhonha e Mucuri, Brasil E-mail: georgia.barros@ufvjm.edu.br

\begin{abstract}
Resumo
A Administração Pública tem recebido diversas contribuições no que diz respeito à utilização de ferramentas que moldam a Gestão das Finanças Públicas (GFP). O Programa de Despesas Públicas e Responsabilidade Financeira (PEFA) avalia a qualidade da GFP em todos os níveis da Administração Pública, considerando informações e dados contidos nos instrumentos de planejamento e orçamento. O PEFA permite desvelar os pontos fortes e fracos dentro da GFP. O objetivo deste estudo foi identificar e discutir como os instrumentos de caráter jurídico e técnico regulamentados a partir da Constituição de 1988 fornecem suporte à adoção do programa PEFA Framework para avaliação da Gestão das Finanças Públicas municipal no período de 2016 a 2020. O método utilizado para a construção desta pesquisa é de Revisão Bibliográfica de Literatura. A pesquisa permitiu identificar que estes instrumentos se complementam e que o PEFA reconhece e aponta as evoluções das reformas apresentadas pelos governos e os resultados obtidos através da agenda de ações implantadas para melhorar a GFP. Ademais, as leis elaboradas para auxiliar na regulamentação do planejamento e orçamento no sentido de direcionar a boa governança e a gestão transparente são alicerces para que o método do programa PEFA Framework seja utilizado na avaliação da GFP municipal.
\end{abstract}

Palavras-chave: Imprecisão orçamentária; Gestão das finanças públicas; Programa de despesas públicas e responsabilidade financeira; Transparência pública.

\begin{abstract}
Public Administration has received several contributions regarding the use of tools that shape Public Financial Management (PFM). The Public Expenses and Financial Responsibility Program (PEFA) assesses the quality of PFM at all levels of Public Administration, considering information and data contained in the planning and budget instruments. PEFA allows the revelation of strengths and weaknesses within the PFM. The objective of this study was to identify and discuss how the legal and technical instruments regulated since the 1988 Constitution provide support for the adoption of the PEFA Framework program for the evaluation of municipal Public Financial Management in the period from 2016 to 2020. The method used for the construction of this research is Bibliographic Review of Literature. The research allowed to identify that these instruments complement each other and that PEFA recognizes and points out the evolution of the reforms presented by the governments and the results obtained through the plan of actions implemented to improve the PFM. In addition, laws designed to assist in the regulation of planning and
\end{abstract}


budgeting in order to direct good governance and transparent management are foundations for the PEFA Framework program method to be used in the evaluation of municipal PFM.

Keywords:Budgetary imprecision; Public financial management; Public expenditure and financial responsibility program; Public transparency.

\section{Resumen}

La Administración Pública ha recibido diversos aportes sobre el uso de herramientas que configuran la Gestión Financiera Pública (GFP). El Programa de Gastos Públicos y Responsabilidad Financiera (PEFA) evalúa la calidad de la GFP en todos los niveles de la Administración Pública, considerando la información y los datos contenidos en los instrumentos de planificación y presupuesto. PEFA permite develar las fortalezas y debilidades dentro de la PFM. El objetivo de este estudio fue identificar y discutir cómo los instrumentos legales y técnicos regulados desde la Constitución de 1988 apoyan la adopción del programa PEFA Framework para la evaluación de la Gestión Financiera Pública municipal en el período de 2016 a 2020. El método utilizado para la construcción de esta investigación es Revisión de Literatura Bibliográfica. La investigación permitió identificar que estos instrumentos se complementan y que el PEFA reconoce y señala la evolución de las reformas presentadas por los gobiernos y los resultados obtenidos a través del calendario de acciones implementadas para mejorar la GFP. Además, las leyes diseñadas para ayudar en la regulación de la planificación y la presupuestación con el fin de orientar la buena gobernanza y la gestión transparente son las bases para que se utilice el método del programa PEFA Framework en la evaluación de la PFM municipal.

Palabras clave: Imprecisión presupuestaria; Gestión financiera pública; Programa de gasto público y responsabilidad financiera; Transparencia pública.

\section{Introdução}

A Administração Pública tem recebido diversas contribuições através de estudos tecnicamente estruturados no sentido de avaliar as principais ferramentas que moldam a Gestão das Finanças Públicas. Para que estas avaliações sejam elaboradas é necessário um suporte legal e técnico em todos os níveis da administração pública para que instrumentos de gestão sejam acessados e as informações estejam disponíveis para a sociedade.

Existem diversos programas utilizados internacionalmente, que avaliam a qualidade da Gestão das Finanças Públicas de um país, estado ou município. De maneira geral, estes programas possuem metodologias próprias e utilizam critérios prédeterminados para avaliar a Gestão das Finanças Públicas de acordo com seu objetivo. É neste contexto que está inserida o programa PEFA - Programa de Despesas Públicas e Responsabilidade Financeira (Public Expenditure and Financial Accountabilty).

A implantação do PEFA recebe amparo legal na Lei 4.320/64, que estatui em seu "Art. $1^{\circ}$ normas gerais de direito financeiro para elaboração e controle dos orçamentos e balanços da União, dos Estados, dos Municípios e do Distrito Federal” (Brasil, 1964, p. 1). Esta Lei é um importante complemento jurídico para abordar a Gestão das Finanças Públicas, alicerçada no Art. 165 da Constituição Federal de 1988, que estabelece as normas para elaboração e execução do ciclo orçamentário (Brasil, 1988,). Nesta perspectiva, a Lei de Responsabilidade Fiscal ou Lei Complementar de n 101/2000 “estabelece normas de finanças públicas voltadas para a responsabilidade na gestão fiscal, com amparo no Capítulo II do Título VI da Constituição" (Brasil, 2000, p. 8). E por fim, a Lei de Acesso à Informação ou Lei de n 12.527/2011, que visa garantir o acesso a informações de autarquias públicas ou entidades privadas sem fins lucrativos ou que recebam recursos públicos (Brasil, 2011).

Determinar instrumentos eficientes para diagnosticar a Gestão das Finanças Públicas municipais, permite compreender como os gestores públicos utilizam ferramentas de planejamento e orçamento, que, muitas vezes, são tratados como peças fictícias elaboradas apenas para cumprimento de exigências legais (Speeden \& Perez, 2020). Tornar público as ações da Administração Pública local acerca de planejamentos, execuções, receitas e despesas orçamentárias é a forma adequada de garantir uma gestão transparente (Belline et al., 2017).

Mesmo sendo possível identificar a utilização do método do programa PEFA em pesquisas anteriores, considerando a gestão pública municipal no Brasil e com intuito de realizar novas investigações é necessário responder a seguinte indagação 
que conduz a determinação do objetivo desta pesquisa: como os instrumentos regulamentados a partir da Constituição de 1988 auxiliam o programa PEFA Framework na avaliação da Gestão das Finanças Públicas municipal no período de 2017-2020?

\section{Metodologia}

Para cumprimento do objetivo proposto, utilizou-se o método da Revisão Bibliográfica realizada através da busca, leitura e análise de documentos publicados que abordam a temática como livros, artigos e demais publicações cientificas. Este trabalho tem caráter qualitativo e integrativo, uma vez que as discussões são realizadas a partir das ideias, conceitos, observações e conclusões realizadas pelos autores dos artigos selecionados (Koche, 2011).

Soares et al. (2018) alicerça nos conceitos de Martins e Theóphilo (2016), Michel (2015), e Gil (2016) para definir a revisão bibliográfica como uma estratégia essencial para realizar uma pesquisa acadêmica, sendo esta uma etapa preliminar e imprescindível do estudo exploratório. Assim, a revisão bibliográfica auxilia no estudo de temas a partir de publicações feitas no meio científico, os quais permitem realizar relevantes discussões, sobretudo quando o tema é caracterizado como complexo e com poucas pesquisas na área (Pereira et al., 2018).

A primeira fase consiste no procedimento realizado a partir de pesquisas em revistas cientificas, utilizando operadores booleanos a partir de palavras-chave definidas. Logo, aplicou-se a seguinte chave com os descritores para busca: [Imprecisão Orçamentária OR Gestão Financeira OR Responsabilidade Financeira OR Despesas Públicas OR Gestão das Finanças Públicas] AND [PEFA OR Avaliação de Desempenho OR Reforma da Gestão das Finanças Públicas].

A pesquisa foi realizada com uso de filtros para que fossem exibidas publicações produzidas nos idiomas inglês e português, datadas a partir dos anos de 2016 até 2020. Destas foram descartadas publicações como, trabalho de conclusão de curso, monografias, teses, e apresentações de seminários e congresso. Excepcionalmente, foram utilizados livros e dissertações de mestrado relevantes que fornecessem maior suporte teórico nesta produção.

Nas fases seguintes, foram baixados os artigos conforme critérios de seleção descritos com base na leitura dos títulos e resumos, e, então realizado um novo processo de triagem a partir da apreciação das publicações pré-selecionadas, sendo indicadas produções as quais foram registradas e catalogadas através da criação de um banco de dados em planilha do Microsoft office excel 2007, distribuídos na seguinte ordem: ano, ISSN, qualis, revista, autor, tema, objetivo e resultados. Na última fase foram extraídas citações diretas pertinentes ao trabalho proposto,e referenciadas na seguinte ordem: autor, ano e página, divididas em tópicos que auxiliaram na construção do referencial teórico dentro do período supracitado.

\section{Resultados}

Os estudos referenciados na bibliografia desta pesquisa permitiram realizar a integração entre apontamentos propriamente teóricos e a utilização prática dos instrumentos técnicos os quais alicerçam a possibilidade de avaliar a Gestão das Finanças Públicas de um município. Os resultados desta integração estão disponibilizados nos cinco subtítulos a seguir.

\subsection{Evolução conceitual do orçamento público no Brasil}

A evolução do orçamento público no Brasil teve início com a Lei 4.320/64, que estatui em seu Art. 1 " "normas gerais de direito financeiro para elaboração e controle dos orçamentos e balanços da União, dos Estados, dos Municípios e do Distrito Federal" (Brasil, 1964, p. 1). Conceitualmente, o orçamento no Brasil pode ser classificado em orçamento tradicional, orçamento programa e orçamento participativo.

O orçamento tradicional, conhecido também como orçamento clássico, parte da perspectiva de que a lei orçamentária envolve as estimativas de receitas e despesas. Em conformidade com esse modelo, não existe inquietação com o planejamento, 
com a intervenção na economia ou com os anseios da população, acrescenta-se que o orçamento é somente um ato que autoriza antecipadamente as receitas e despesas públicas (Paludo, 2013).

O orçamento tradicional prevaleceu até o ano de 1964, com respaldo da Constituição Federal vigente no período. Por se tratar de uma época em que o país se encontrava sob o regime militar, o orçamento era composto apenas de despesas e receitas, não se fazia o uso das ferramentas de planejamento e não existia programação de objetivos, metas, e recursos reais, o que ocasionou regras orçamentárias que não vislumbrava o interesse social, mas do próprio governo e de suas políticas (Vale \& Silva, 2018).

A melhor forma de compreender sobre as mudanças da estrutura do orçamento público no Brasil é realizar a contraposição do orçamento tradicional com o orçamento moderno denominado Orçamento Programa, pois neste modelo é possível verificações sob os conceitos da eficiência, eficácia, economicidade e efetividade das contas públicas (Vale \& Silva, 2018).

$\mathrm{O}$ orçamento programa permite que seus gastos sejam realizados dentro de programas governamentais e que tenha indicadores de acompanhamentos, objetivando melhor controle externo e controle social. Neste aspecto, garante maior possibilidade de "controle sobre as ações, objetivos, metas e resultados alcançados pelo Estado e pelas despesas por ele realizadas e, por extensão, possibilita também um maior controle sobre as políticas públicas por ele implantadas" (Santos et al., 2017, p. 198).

A Lei 4.320/64 determina as diretrizes para que o orçamento seja implantado nastrês esferas do governo brasileiro, relacionando-se aos programas em inúmeros de seus dispositivos (Brito et al., 2020). Entretanto Azevedo (2013) complementa que foi somente na primeira década do século XXI que o Brasil passou a seguir com rigor essa determinação.

(...) Lei 4.320/64 exerceu o papel de determinar a classificação do orçamento por meio de programas, mas foi na última década que o país de fato implementou tal metodologia, que hoje é adotada por todas as esferas no país, fazendo com que o orçamento seja elaborado a partir de um diagnóstico, e definindo metas físicas para cada tipo de gasto incluindo no orçamento, além de indicadores de acompanhamento (Azevedo, 2013, p. 38).

Quanto ao orçamento participativo, seu conceito é definido como "uma técnica orçamentária em que a alocação de alguns recursos contidos no orçamento público é decidida com a participação direta da população" (Paludo, 2013, p. 28). O autor acrescenta que a participação pode ser ampliada aos "grupos organizados da sociedade civil", bem como a "associação de moradores" e que esse modelo cabe somente aplicação na esfera municipal, e que seu principal benefício é a "democratização da relação do Estado-sociedade com o fortalecimento da democracia".

Segundo Giacomoni (2019), desde 1990 o orçamento participativo é o instrumento mais conhecido, indicado e utilizado para se fazer participação social. Em um conceito sintetizado, o orçamento participativo é um "processo regulamentado, de caráter anual", onde a sociedade pode participar das escolhas das "obras e serviços que integrarão os planos e orçamentos públicos".

No orçamento participativo é garantida a participação da população para manifestar onde serão atribuídos os recursos relativos aos seus impostos, possibilitando maior eficiência e transparência. Posteriormente, após definidas as prioridades juntamente com os governantes municipais, serão autorizadas o acompanhamento da sua aplicabilidade e execução. Contudo, o real interesse entre sociedade e governantes locais na "preparação, no cumprimento e no andamento do orçamento" permitirá que os recursos públicos sejam executados e priorizados em demandas de maior indigência da população (Costa, 2017).

Dentre os orçamentos apresentados, o orçamento programa é o modelo cuja metodologia é utilizada na elaboração orçamentária no Brasil para atender as exigências legais do ciclo orçamentário representados pelos PPA, LDO e LOA. Sendo 
assim, é importante destacar que uma avaliação da GFP municipal utilizará os orçamentos programas definidos pela administração pública local em seu planejamento orçamentário (Azevedo, 2013).

\subsection{Transparência e boa governança}

A transparência está relacionada com aspublicações de informações por parte de órgãos que possibilitam agentes externos fiscalizarem e em seguida aprovar seu funcionamento interno e desempenho. Neste sentido, a transparência pode ser desenvolvida sob duas perspectivas, a primeira como proativa, "denominada transparência ativa", ou pode ser simplesmente uma resposta, das várias perguntas realizadas pela sociedade, "denominada transparência passiva". A transparência viabiliza o monitoramento e avaliação do desempenho de gestores e agentes públicos, pode-se dizer que é uma grande aliada da boa governança e da qualidade institucional. Constitui-se através de interações entre diversos "atores políticos e sociais, dentro do conjunto de regras formais e informais", que possibilitam o uso de diversas tecnologias, buscando permanentemente a evolução (Baldissera et al., 2020, p. 341).

Os processos recentes de reforma da gestão pública têm a transparência como uma de suas principais bases. A ideia de que os dados e informações geradas pelo setor público devem ser livremente acessados pela sociedade é cada vez mais presente na visão de administradores públicos em todo o mundo. A transparência é considerada um requisito para uma boa governança. Diamond (2003) acredita que a exposição de dados força governos a modificar as políticas do passado e, por isso, tem ajudado a alcançar a disciplina fiscal e melhoria na alocação de recursos (Speeden\& Perez, 2020, p. 6).

Contudo, a transparência e a qualidade do orçamento estão diretamente relacionadas. $\mathrm{O}$ autor salienta que a transparência não se deve apenas ao entrosamento do "governo com o legislativo e com o público, mas também aos processos e procedimentos internos para a construção de informações fiscais e sua revisão" (Speeden \& Perez, 2020, p. 6). A transparência é um dos princípios orçamentários da governança pública, e que considera o aperfeiçoamento dos "mecanismos de transparência da gestão pública" como hábitos de boa governança (Cruz \& Afonso, 2018).

Neste sentido, para seguir as práticas de boa governança será necessário o cumprimento inicialmente dos cinco princípios determinados na Constituição Federal no seu Artigo 37, definindo que, a administração pública direta e indireta de qualquer dos Poderes da União, dos Estados, do Distrito Federal e dos Municípios obedecerá aos princípios de legalidade, impessoalidade, moralidade, publicidade e eficiência (Brasil, 1988). Estes princípios possuem ligação mútua, não sendo possível falar de seus conceitos de modo isolado.

\subsection{Ciclo orçamentário e gestão das finanças públicas}

O ciclo orçamentário é o período que compete o exercício das atividades orçamentárias que envolvem as fases de elaboração, estudo e aprovação, execução e avaliação e controle (Almeida \& Costa, 2019).

Para se chegar ao modelo atual, o orçamento passou por diversas transformações até a promulgação da Constituição Federal de 1988 quando deu início à segunda fase da evolução orçamentária no Brasil, chamada por Azevedo e Aquino (2016)de pós-constitucional e que trouxe mudanças significativas no orçamento público como sua associação a planejamentos através de instrumentos como o Plano Plurianual (PPA) com definição de metas de governo desdobrado anualmente através da Lei de Diretrizes Orçamentárias (LDO) e a Lei Orçamentária Anual (LOA).

Speeden e Perez (2020) apontam que estes três instrumentos são hierárquicos e integrados. O PPA tem por função normatizar as atividades de gestão para um período de quatro anos com definição de objetivos, ações e metas (Costa, 2017). Contudo, é importante frisar que o período de gestão do poder executivo na administração pública não é o mesmo período estabelecido no PPA, uma vez que o gestor em seu primeiro ano de mandato seguirá o planejamento do último ano do PPA 
anterior, prevalecendo assim à execução dos três primeiros anos do PPA elaborado para sua gestão nos três anos finais (Almeida \& Costa, 2019).

A LDO estabelece as prioridades para o ano seguinte (Speeden\& Perez, 2020)e conduz a elaboração da LOA no sentido de organizar metas e objetivos para o prazo de um ano (Almeida \& Costa, 2019). A LOA estima e define as receitas e despesas para o ano fiscal sendo elaborada conforme planejamento do PPA e direcionamento da LDO (Speeden \& Perez, 2020; Almeida \& Costa, 2019).

Contudo, muitos dos municípios brasileiros não utilizavam o modelo de gestão orçamentária proposta pela Constituição Federal de 1988 no sentido de utilizar o PPA, a LDO e a LOA como instrumentos de planejamento da Gestão das Finanças Públicas (Azevedo \& Aquino, 2016). A falta de engajamento dos municípios para utilizar os instrumentos do ciclo orçamentário fez emergir a necessidade de uma lei para regulamentar a utilização na administração pública em todas as suas esferas de gestão.

No ano de 2000 foi aprovada a Lei Complementar no 101/2000 que ficou conhecida como Lei de Responsabilidade Fiscal (LRF) que exigiu determinados conteúdos como estabelecimento de metas e riscos fiscais e outras providências para a elaboração do PPA e da LDO tornando-as mais complexas na sua estrutura (Azevedo \& Aquino, 2016; Almeida \& Costa, 2019).

A LRF contribuiu para o direcionamento de uma gestão mais transparente na Administração Pública no Brasil por exigir ampla publicação de relatórios, planos orçamentários, prestações de contas, entre outros, principalmente através da internet (Belline et al, 2017). Além disso, limites no planejamento orçamentário, como, por exemplo, o equilíbrio de contas com restrição das despesas limitadas à previsão de receitas (Speeden\& Perez, 2020).

Contudo, com objetivo de garantir maior transparência de gestão na administração pública, a LRF recebeu novas contribuições através da Lei Complementar no 131/2009, conhecida como Lei da Transparência que propôs um maior estímulo para a participação popular na elaboração dos planos e metas dos governos em todas as suas esferas. (Belline et al., 2017).

No entanto, o direito ao acesso à informação garantido constitucionalmente somente veio a ser regulamentado através da Lei $n^{\circ}$ 12.527/2011 que ficou conhecida como Lei de Acesso à Informação (LAI). A LAI abrange todas as instituições e órgãos públicos da administração direta e indireta, incluindo as entidades privadas que recebem recursos públicos (Carli \& Fachin, 2017; Belline et al., 2017).

Estes marcos regulatórios proporcionam o exercício da transparência ativa e passiva da administração pública e as atividades dos mecanismos de controle que acompanham os governos em suas gestões.

\subsection{Mecanismos de controle}

Uma das formas de estimular a boa governança utilizando a transparência como aliada é a existência dos mecanismos de controles, que garante a fiscalização da Gestão das Finanças Públicas da administração pública direta e indireta. Dentro do ordenamento jurídico brasileiro, pode-se dizer que as atividades de controle e a avaliação da execução orçamentária e financeira estão elencadas na Constituição Federal, nas Constituições estaduais, na Lei n $4.320 / 64$, nas legislações orgânicas municipais, na Lei de Responsabilidade Fiscal, na Lei de Acesso à Informação e na Lei Orgânica do TCU. Nesta percepção, foram criados os três sistemas de controle: interno, externo e social. Tanto o controle interno quanto o externo são deliberados pela Constituição Federal de 1988 no Art. 70 (Giacomoni, 2019).

Para Giacomoni (2019), o controle social é definido pelos diferentes tipos de participação social, como no envolvimento da sociedade civil na formulação, acompanhamento e controle de ações que são de responsabilidade do poder público. Mencionado na Carta Magna por diversos dispositivos, a participação e o controle social são exercidos pelos variados tipos de conselhos, como: o conselho da saúde, educação e assistência social. 
Um dos fatores para justificativa dos mecanismos institucionais de controle está atrelado ao voto, uma vez que, por mais que aconteça de forma democrática não consegue assegurar o controle por inteiro dos governantes, visto que a avaliação segue um retrospecto. Neste sentido, a justificativa acima é reforçada com a necessidade de instrumentos de fiscalização que possam assegurar a participação da sociedade civil nas decisões de cunho coletivo (Cruz \& Afonso, 2018).

Nos municípios, a fiscalização é de competência do Poder Legislativo e do Tribunal de Contas por meio do controle externo, e pelo Poder Executivo através do controle interno (Cruz \& Afonso, 2018). Bezerra et al. (2017), corrobora com o texto da CF/88 Art. 70 e acrescenta que os Tribunais de Contas instituem normas internas onde é estabelecido prazos e rotinas a serem observados pelos entes jurisdicionados, e que busca realizar suas atividades com presteza e padronização.

No caso dos Tribunais de Contas, o principal objetivo é realização de auditorias para certificar a probidade das execuções da administração pública (Fernandes \& Teixeira, 2020). Nesta perspectiva, Heller (2019, p. 16) menciona que o Tribunal de Contas visa garantir que os "agentes públicos" obedeçam às determinações legais, "com vista à proteção do erário e à promoção da boa administração", assegurando assim os direitos da população.

Neste sentido, Bezerra et al. (2017), descreve a importância da prestação de contas nos municípios ressaltando que:

É por meio da prestação de contas que as informações sobre as receitas e os gastos públicos são apresentadas aos órgãos competentes e à sociedade. A prestação de contas, no âmbito municipal, inicia-se com os relatórios contábeis produzidos por servidores dos entes públicos ou por prestadores de serviços de contabilidade pública. Posteriormente, as informações financeiro-contábeis são apresentadas ao e analisadas pelo órgão de controle externo (Tribunal de Contas do Estado) (Bezerra et al., 2017, p. 53).

O arquivamento e a manutenção correta de documentos contábeis são imprescindíveis para os municípios para que sejam considerados materiais integrantes da prestação de contas dos municípios perante os órgãos de controle externo, conforme determinado pelo Art. 31 da Constituição Federal de 1988 (Bezerra et al., 2017).

\subsection{Avaliação do orçamento público pelo programa PEFA}

O PEFA - Programa de Despesas Públicas e Responsabilidade Financeira (Public Expenditure and Financial Accountabilty) é um programa desenvolvido em 2001 a partir de cooperação internacional realizado pela Comissão Europeia, FMI (Fundo Monetário Internacional), Banco Mundial, Ministério das Finanças da República Eslovaca, e Governos da França, Noruega, Suíça e Reino Unido, com o objetivo de estruturar uma metodologia padronizada para avaliar a Gestão das Finanças Públicas. A metodologia do programa PEFA já foi utilizada em mais de 149 países sendo emitidos mais de 500 relatórios em sua história, é atualmente considerada um dos mais abrangentes indicadores dentro do campo da Administração Pública (Pefa, 2019; Hadley \& Miller, 2016).

O PEFA, além de ter objetivo de avaliar a Gestão das Finanças Públicas, possui também a finalidade de auxiliar na identificação dos níveis de imprecisão orçamentária da instituição avaliada.

A estrutura do programa PEFA possibilita verificar a imprecisão das receitas e despesas considerando o valor inicial fixado no orçamento e o valor executado com limite de variação entre o previsto e o realizado (Azevedo, 2013). Os 31 indicadores do programa PEFA que auxiliam na avaliação da Gestão das Finanças Públicas são divididos entre os campos de credibilidade e orçamento, transparência das finanças públicas, gestão de ativos e passivos, estratégia fiscal política e orçamentária, controle de execução, relatórios contábeis e controle externo. O programa pode ser utilizado em níveis de governo central, estadual, provincial e municipal (Carneiro, 2018; Pefa, 2019).

O programa PEFA é apontado como um apoio à Gestão das Finanças Públicas que compara as despesas e receitas realizadas com orçamento aprovado, atrasos de pagamentos, acesso à informação disponível ao cidadão, método e participação 
da sociedade na composição do orçamento, auditorias, fiscalização do poder legislativo entre outras variáveis que são importantes para uma administração pública democrática e eficiente (Melo \& Silva, 2016).

Alt (2019) considera o PEFA um pilar para avaliar prestações de contas que sugere gerar um padrão de credibilidade para as instituições considerando diversas variáveis financeiras e de transparência. $\mathrm{O}$ autor opina que os resultados podem ser "familiares" devido às deficientes previsões das receitas e utilização de despesas suplementares.

Loozekoot e Dijkstra (2017) adicionam que o quadro do PEFA aponta para seis pilares para um sistema transparente de gestão pública, sendo quatro direcionados para o ciclo orçamentário e dois direcionados para credibilidade orçamentária. Atribuíram para os pilares do ciclo orçamentário, o planejamento, a implementação e elaboração dos relatórios, a auditoria e para a credibilidade orçamentária, indicadores definidospela OCDE que representam boas práticas nos processos, sistemas e procedimentos.

Vasishta e Thakur (2018) enaltecem sobre a evolução do PEFA ao longo dos anos e vem sendo cada vez mais utilizado para avaliar a GFP de governos nacionais e subnacionais como estado, regiões e municípios.

Os Governos usam o PEFA para obter uma visão do desempenho da sua própria GFP. O PEFA oferece uma base comum para examinar o desempenho da GFP nos Governos nacionais e subnacionais. Para além dos Governos, outros usuários do Quadro PEFA são as organizações da sociedade civil e instituições internacionais de desenvolvimento. As pontuações e relatórios PEFA permitem que todos os utilizadores da informação obtenham uma visão geral dos pontos fortes e fracos do sistema de GFP de um determinado país. Os utilizadores verificam também as implicações que os resultados globais de desempenho têm sobre os objetivos fundamentais da disciplina fiscal, da alocação estratégica de recursos e da prestação eficiente de serviços. A análise PEFA contribui, assim, para o diálogo sobre a necessidade e as prioridades para a reforma da GFP (Pefa, 2019, p. 9).

Contudo, o PEFA não indica reformas para a GFP após os resultados obtidos nas avaliações, porém, reconhece e aponta as evoluções das reformas apresentadas pelos governos e os resultados obtidos através da agenda de ações implantadas para melhorar a GFP.

\section{Discussão}

\subsection{Instrumentos técnicos de apoio para uso da PEFA}

Zielinski et al. (2017) ao realizarem uma pesquisa para identificar a imprecisão orçamentária de quatro municípios do estado do Paraná e compará-las, utilizaram na metodologia de pesquisa a obtenção de dados através dos portais de transparências dos municípios eleitos para a investigação. Assim, obtiveram acesso a relatórios orçamentários, demonstrativos contábeis, despesas e receitas aprovadas e executadas, além de outros relatórios similares contendo dados exigidos pelo programa PEFA para análise da imprecisão orçamentária dos municípios em um espaço temporal de três anos. Os estudos realizados com a utilização dos instrumentos técnicos apontados permitiram identificar os municípios que conseguiram maior acurácia na estimação de receitas e de despesas em campos específicos com receitas de IPTU, ISS e despesas correntes, de pessoal, entre outros.

Aquino e Azevedo (2015) publicaram uma pesquisa sobre o irrealismo orçamentário a partir dos municípios no Brasil com o foco nas estimativas de receitas e despesas de origem local e estadual. Para obter as informações, foi necessário que os pesquisadores acessassem também relatórios sobre estimativas e execuções orçamentárias para que o objetivo da investigação obtivesse êxito. E para aplicar os dados obtidos, os autores utilizaram referências de índices do programa PEFA para estimar o nível de realismo orçamentário para receitas e despesas de cada município avaliado.

Os resultados da pesquisa, considerando as receitas, apontaram que apenas $10 \%$ dos municípios brasileiros possuem alto índice de realismo orçamentário e pouco mais da metade, na ordem de 58\%, apresentam taxas de variação permitidas pela 
escala do programa PEFA. Com relação às despesas, os autores apontam que os municípios realocam em média $25 \%$ das destinações previstas durante o processo de execução do orçamento.

Aquino e Azevedo (2015) também comentam quanto à superestimação ou subestimação das previsões das receitas orçamentárias alertando:

Por um lado municípios podem subestimar receitas gerando excesso de arrecadação na execução (caso permitido pelo legislativo na LOA) e então abrir créditos adicionais alocando despesas com um menor escrutínio pelo legislativo. Por outro lado podem superestimar a receita, caso o legislativo não conceda autorizações elevadas para a abertura de créditos adicionais, e dessa forma escolhem ex post qual programa alocarão os recursos, e os demais simplesmente não serão executados. Com isso evita-se o momento da barganha com o legislativo, pois as despesas já foram aprovadas previamente (Aquino \& Azevedo, 2015, p. 13).

Neste sentido, os autores sugerem que as avaliações realizadas por programas como o PEFA deveriam considerar as alterações orçamentárias de caráter incrementalista como mudanças de gastos e abertura de créditos adicionais.

Zielinskiet al. (2017) ao utilizarem o método do programa PEFA, concluíram em seus resultados que, a subestimação da receita ou a superestimação das despesas é a principal causa para a imprecisão orçamentária nos municípios, corroborando as impressões dos estudos realizados por Aquino e Azevedo (2015). Nesta perspectiva acrescenta-se a necessidade de um planejamento condizente, um sistema de controle eficiente, e a elaboração do orçamento com foco na realidade municipal, pois, o que se estima não é compatível com a realidade arrecadada (Zielinskiet al., 2017).

Com relação à imprecisão orçamentária e a utilização do programa PEFA para avaliar a GFP de um ente público Aquino e Azevedo (2015) colocam em pauta a hipótese levantada por Rubin (2014) quanto à intencionalidade na existência das distorções orçamentárias desde a sua elaboração.

Não obstante, é possível identificar uma similaridade de pensamento na condução interpretativa dos instrumentos técnicos orçamentários para a utilização da metodologia do PEFA para analisar a Gestão das Finanças Públicas de um município. Mais além, percebe-se a congruência na identificação das prováveis origens que dificultam o uso de instrumentos técnicos disponibilizados pelos entes públicos.

\subsection{Instrumentos de caráter jurídico de apoio para o uso da PEFA}

A instrumentalização técnica para avaliar a Gestão das Finanças Públicas somente é possível devido ao aparato jurídico que regulamenta as atividades dos entes públicos para uma administração transparente.

Aquino e Azevedo (2015) alicerçam sua pesquisa utilizando instrumentos orçamentários que, apesar de terem uma elaboração técnica, podem ser considerados mecanismos de apreciação jurídica. Ao realizarem um estudo sobre o grau de realismo orçamentário de municípios do Brasil, eles fundamentaram a estrutura da pesquisa a partir das leis que regem o ciclo orçamentário tal como referenciado na bibliografia desta pesquisa. Sendo assim, utilizam o PPA, a LDO e LOA para cumprir os objetivos propostos.

A adoção e efetiva implantação do ciclo orçamentário (tal como idealizado) nos municípios brasileiros ainda é um processo em andamento. Evidentemente, a totalidade dos municípios brasileiros executa com relativa frouxidão o ciclo completo, cumprindo a parte objetiva da legislação para estarem autorizados a executar o orçamento, em outras palavras possuem formalmente uma LDO e uma LOA aprovadas pelo legislativo. Contudo o nível de uso de LDO e LOA como instrumentos de planejamento (além da simples confecção e aprovação da proposta de orçamento) varia entre os municípios. Ainda, observando as etapas anteriores como PPA e Plano Diretor, ainda mais frágil é o planejamento municipal (Aquino \& Azevedo, 2015, p. 4). 
Zielinski et al. (2017, p.34) destacam a LRF ao realizar seus estudos utilizando o programa PEFA e adiciona que a referida "exige uma gestão planejada e transparente, estabelecendo metas fiscais, objetivos mais rígidos e a obrigatoriedade do cumprimento dessas metas, assim como possui normas eficientes, auxiliando na prevenção de riscos e desvios".

No entanto, Andrade (2018) aponta sobre alterações permitidas previstas na constituição através do Art. 167 para ajuste orçamentário prevendo transposições, remanejamentos e transferências orçamentárias.

Aquino e Azevedo (2015) mencionam o artigo 16 da LRF que exige que o aumento de despesas das ações governamentais seja relatado em demonstrativos específicos na LDO. Segundo os autores, este e outros artigos aumentam a prática do incrementalismo orçamentário.

Os autores citados neste tópico, de maneira geral, ao utilizarem a metodologia do programa PEFA referenciam os instrumentos jurídicos que regulamentam o orçamento público sugerindo que estes sejam essenciais para lograr êxito em suas pesquisas.

\section{Conclusão}

A pesquisa realizada buscou compreender sobre como os instrumentos técnicos e jurídicos advindos a partir da Constituição Federal de 1988 podem contribuir na avaliação da Gestão das Finanças Públicas de um município através da adoção da metodologia do programa PEFA.

O trabalho apresentado permitiu colocar em evidência a importância dos instrumentos de caráter técnico e jurídico que servem de suporte para que o programa PEFA seja aplicado para avaliar a Gestão das Finanças Públicas (GFP) em todos os níveis da Administração Pública no Brasil.

Os estudos identificaram que estes instrumentos são complementares, e mesmo que sejam técnicos, recebem a nomenclatura de Lei como é o caso do Plano Plurianual (PPA), a Lei de Diretrizes Orçamentárias (LDO) e a Lei Orçamentária Anual (LOA).

As leis que complementam a regulamentação da GFP no Brasil trazem instrumentos estritamente técnicos para uma possível avaliação dos instrumentos de planejamento e orçamento como os relatórios de execução orçamentária, balanços e demonstrativos que devem estar disponíveis nos portais de transparência.

O acesso às informações da administração pública em qualquer nível de gestão somente é possível devido à existência de leis que complementam a legislação orçamentária e o acesso à informação pública no sentido de estimular os mecanismos de controle no acompanhamento das ações governamentais. Neste sentido, ficam em evidência a Lei de Responsabilidade Fiscal e a Lei de Acesso à Informação como exemplos de instrumentos jurídicos que oferecem suporte na avaliação da Gestão das Finanças Públicas de um município.

Contudo, mesmo que estes instrumentos sejam utilizados para avaliar a Gestão das Finanças Públicas através da metodologia do programa PEFA, é preciso atenção quanto aos procedimentos adotados pela administração pública que podem aumentar o nível de discricionariedade orçamentária.

Para estudos futuros, é importante considerar outras publicações internacionais aplicadas através da adoção do programa PEFA, e também, abordar os níveis de discricionariedade orçamentária e outros fatores que podem influenciar os resultados da avaliação GFP municipal.

\section{Referências}

Almeida, H. M. de, \& Costa, A. V. (2019). Orçamento Público como mecanismo de planejamento para a gestão. Id OnLine Revista Multidisciplinar e de Psicologia. 13 (43), p. 559-577. https://doi.org/10.14295/idonline.v13i43.1555

Alt, J. E. (2019). Twenty Years of transparency research. Public Sector Economics. 43. p. 5-13. https://doi.org/10.3326/pse.43.1.2 
Andrade, J. A. de. (2018). Risco Orçamentário nos estados brasileiros e no Distrito Federal: uma proposta de aplicação de técnicas de trackingerror sobre as despesas públicas. Dissertação. Mestrado. Universidade Federal de Minas Gerais.

Azevedo, R. R. de, \& Aquino, A. C. B. de. (2016). O planejamento em municípios de pequeno porte em São Paulo. Revista De Contabilidade E Organizações, 10(26), 63-76. https://doi.org/10.11606/rco.v10i26.111202

Aquino, A. C. B. de, \& Azevedo, R. R. de. (2015). O "IR" realismo orçamentário nos municípios brasileiros. Business and Management Review, 5(1), 210224. http://www.businessjournalz.org/Brazil\%20Special\%20Edition/SI\%20June,\%202015/BMR(00571)-V5-N01-June-2015-SI-VIII-19.pdf

Azevedo, R. R. de. (2013). Imprecisão na Estimação Orçamentária dos Municípios Brasileiros. Ribeirão Preto. USP. Dissertação. Mestrado. Faculdade de Economia, administração e Contabilidade de Ribeirão Preto/USP. https://www.teses.usp.br/teses/disponiveis/96/96133/tde-17032014-110156/pt-br.php

Baldissera, J. F., Dall'Asta, D., Casagrande, L. F., \& Oliveira, A. M. B. de. (2020). Influência dos aspectos socioeconômicos, financeiro-orçamentários e político-eleitorais na transparência dos governos locais. Revista de Administração Pública, 54(2), 340-359. https://doi.org/10.1590/0034-761220190048

Belline, E. C. de O., Silva, A. C. B. da., Albuquerque, F. dos S., \& Silva. V. da. (2017). Transparência Pública, Um Caminho Sem Volta: Descrição das informações que devem constar nos portais governamentais. Id onLine Revista Multidisciplinar Psicologia, 11 (37). 80-102. https://doi.org/10.14295/idonline.v11i37.808

Bezerra, S., Lima, M., \& Paiva, S. (2017). Informações contábeis de municípios: Superação de erros através da gestão do conhecimento. Qualitas Revista Eletrônica, 18(1), 52-67. http://dx.doi.org/10.18391/req.v18i1.2977

Brito, T. M. de, Santos, A. T. O., Dias, C. A. \& Santos, C. M. (2020). Garantia dos direitos fundamentais através das funções estatais na execução do orçamento público: uma revisão integrativa da produção científica dos últimos dez anos, Research, SocietyandDevelopment (9)5. http://dx.doi.org/10.33448/rsd-v9i5.2890.

Brasil. (1988). Constituição da República Federativa do Brasil. http://www.planalto.gov.br/ccivil_03/constituicao/constituicao.htm

Brasil. (1964). Lei n. 4.320. Estatui Normas Gerais de Direito Financeiro para elaboração e controle dos orçamentos e balanços da União, dos Estados, dos Municípios e do Distrito Federal. http://www.planalto.gov.br/ccivil_03/Leis/L4320.htm

Brasil. (2000). Lei Complementar n. 101. Estabelece normas de finanças públicas voltadas para a responsabilidade na gestão fiscal e dá outras providências. http://www2.senado.leg.br/bdsf/handle/id/70313

Brasil. (2011). Lei n. 12.527. Regula o acesso a informações previsto no inciso XXXIII do art. $5^{\circ}$, no inciso II do $\S 3^{\circ}$ do art. 37 e no $\S 2^{\circ}$ do art. 216 da Constituição Federal; altera a Lei ${ }^{\circ} 8.112$, de 11 de dezembro de 1990; revoga a Lei $n^{\circ} 11.111$, de 5 de maio de 2005 , e dispositivos da Lei ${ }^{\circ}$ 8.159, de 8 de janeiro de 1991; e dá outras providências. http://www.planalto.gov.br/ccivil_03/_ato2011-2014/2011/lei/112527.htm

Carli, D., \& Fachin, G. (2017). A Lei de Acesso à Informação e a gestão de documentos. Biblios: Journal of Librarianship and Information Science, 0(66), 4759. https://doi.org/10.5195/biblios.2017.308

Carneiro, B. de O. (2018). Uma proposta de avaliação da governança na gestão orçamentária dos estados brasileiros. Dissertação. Mestrado. Universidade Federal do Ceará. Fortaleza. http://repositorio.ufc.br/handle/riufc/37883

Costa, W. P. da. (2018). Orçamento público: a importância do orçamento participativo na gestão pública. Revista Controle - Doutrina e Artigos, 15(2), 210234. https://doi.org/10.32586/rcda.v15i2.389

Cruz, C. F. da, \& Afonso, L. E. (2018). Gestão fiscal e pilares da Lei de Responsabilidade Fiscal: evidências em grandes municípios. Revista de Administração Pública, 52(1), 126-148. https://dx.doi.org/10.1590/0034-7612165847

Fernandes, G. A. A., \& Teixeira, M. A. C. (2020). Accountability ou Prestação de Contas, CGU ou Tribunais de Contas: o exame de diferentes visões sobre a atuação dos órgãos de controle nos municípios brasileiros. BASE - Revista de Administração e Contabilidade da Unisinos. 17(3), 456-482. https://doi.org/10.4013/base.2020.173.04

Giacomoni, J. (2019). Orçamento governamental: teoria, sistema, processo. Atlas.

Hadley, S. \& Miller, M. (2016). PEFA: What is it good for? The role of PEFA assessments in public financial management reform. ODI Discussion. https://www.odi.org/sites/odi.org.uk/files/resource-documents/10484.pdf

Heller, G. (2020). Diálogos Institucionais e Participação Social: A legitimidade do Tribunal de Contas no controle das políticas públicas. Revista Direito das Políticas Públicas, 1(2), 148-171. http://seer.unirio.br/index.php/rdpp/article/view/9143

Loozekoot, A., \& Dijkstra, G. (2017). L'imputabilité publique et le Programme PEFA (programme d'examen des dépenses publiques et d'évaluation de la responsabilité financière, Revue Internationale des Sciences Admintratives, 4 (83), 817-838. Recuperado de https://www.cairn.info/revue-internationale-dessciencesadministratives-2017-4-page-817.htm

Melo, C. A. V. de, \& Silva, L. M. F. da. (2016). Boa Gestão e Políticas Públicas Municipais. Revista de Ciências Sociais. 47 (2), 163 -196. http://www.periodicos.ufc.br/revcienso/article/view/6303

Paludo, A. V. (2013). Orçamento público e administração financeira e orçamentária e LRF. (4a ed.), Elsevier.

PEFA (2019). Manual do Quadro de Avaliação da Gestão das Finanças Públicas. Secretariado PEFA. 1818 H Street NW, Washington DC 20433, EUA.

Pereira, A. S., Sthitsuka, D. M., Pereira, F. J., \&Shitsuka, R. (2018). Metodologia da Pesquisa Científica, Universidade Federal de Santa Maria. https://repositorio.ufsm.br/bitstream/handle/1/15824/Lic_Computacao_Metodologia-Pesquisa-Cientifica.pdf?sequence=1.

Köche JC. (2011) Fundamentos de metodologia científica: teoria da ciência e prática da pesquisa. Vozes. 
Research, Society and Development, v. 10, n.4, e4010413663, 2021

(CC BY 4.0) | ISSN 2525-3409 | DOI: http://dx.doi.org/10.33448/rsd-v10i4.13663

Santos, F. R. dos, Jankoski, A. R.M.C., Oliveira, A. G. de, \&Rasoto, V. I. (2017). O orçamento-programa e a execução das políticas públicas. Revista Do Serviço Público, 68(1), 191-212. https://doi.org/10.21874/rsp.v68i1.1038

Soares, S. V., Picolli, I. R. A., \& Casagrande, J. L. (2018). Pesquisa Bibliográfica, Pesquisa Bibliométrica, Artigo de Revisão e Ensaio Teórico em Administração e Contabilidade. Administração: Ensino E Pesquisa, 19(2), 308-339. https://doi.org/10.13058/raep.2018.v19n2.970

Speeden, E. A., \& Perez, O. C. (2020). Fatores que impactam na qualidade do planejamento orçamentário dos municípios do estado de São Paulo. Administração Pública E Gestão Social. https://doi.org/10.21118/apgs.v12i1.5517

Vale, P. C. B do., \& Silva, M. V. D. de C. (2018). Legalidade ou "4S"? Estudo sobre as principais mudanças nas análises de pareceres e relatórios emitidos por Instituições de Controle Interno e Externo perante o Orçamento Tradicional e o Orçamento Programa. Revista de Contabilidade UFBA. 12 (1), 186-208. http://dx.doi.org/10.9771/rc-ufba.v12i1.18387

Vasishta, S., \& Thakur, D. (2018).Assessment of the Public Finance Management and Accountability systems of the Municipal Corporation of Gurugram. WorkingPaper Series. SymbiosisSchoolofEconomics.

Zielinski, C. F., Hirt, J. de F., \& Witt, C. (2017) Nível de imprecisão orçamentária dos municípios da região da Amsulep. Revista Brasileira de Contabilidade. 223, 33-43, https://docplayer.com.br/112685997-Nivel-de-imprecisao-orcamentaria-dosmunicipios-da-regiao-da-amsulep.html 